\title{
O percurso Criativo Contínuo da Luz
}

The continuous course of the creative process of light

Jociel Carvalho Teixeira ${ }^{1}$

Fernando Lira Ximenes ${ }^{2}$ 


\section{Resumo}

Este artigo propõe um olhar reflexivo da iluminação cênica como uma linguagem artística que compõe a cena e que está inserida em um processo criativo contínuo e evolutivo. Partindo do pensamento de Salles (2008) sobre a construção da obra de arte, relacionando aos conceitos de Camargo (2015) e de outras vivências como as de Vasquez (2015), aliando à prática do trabalho profissional do iluminador, o objetivo desse artigo é repensar e questionar sobre a forma que a luz é pensada, executada e inserida, através da análise da prática de criação e a execução da iluminação, destacando algumas experiências com a operação de luz no trabalho Máquina Fatzer - Diga que Você Está de Acordo (2014).

Palavras-chave: Iluminação cênica; processo criativo; gesto inacabado; operação de luz

\section{Abstract}

This article proposes a reflective look at scenic lighting as an artistic language that composes the scene and is embedded in a continuous and evolving creative process. Starting from the thought of Salles (2008) about the construction of the work of art, relating to the concepts of Camargo (2015) and other experiences like those of Vasquez (2015), allied to the professional work of the illuminator. In this way, the objective of this article is to rethink and question about the way light is thought, executed and inserted, through the analysis of the practice of creation and the execution of lighting, highlighting some experiments with light operation at work Máquina Fatzer - Diga que Você Está de Acordo (2014).

Keywords: Scenic lighting, creative process, unfinished gesture, light operation

ISSN: 1414.5731

E-ISSN: 2358.695

${ }^{1}$ Mestrando no Programa de Pós-Graduação em Artes - Instituto Federal de Educação, Ciência e Tecnologia do Estado do Ceará (IFCE). cielceni@gmail.com

${ }^{2}$ Prof. Dr. Instituto Federal de Educação, Ciência e Tecnologia do Ceará (IFCE). fernandoliraximenes@gmail.com 


\section{Introdução}

O presente artigo é o recorte de uma investigação, que ainda está em processo acerca do percurso criativo da luz cênica. Para essa investigação, partimos de materiais teóricos em teatro, luz e artes em geral e, de nossas experiências profissionais, adquiridas no decorrer do trabalho profissional com a iluminação cênica. Por intermédio destes, propomos a reflexão e questionamento do processo criativo da luz cênica como algo contínuo e a sua co-evolução paralelamente à cena. Acreditamos que a luz cênica é uma linguagem artística que compõe e se realiza por meio da cena.

Para Salles (2008), o processo criativo artístico é algo contínuo, está sempre em evolução e com uma complexidade existente em suas metamorfoses e, com esta incompletude, estabelece um valor dinâmico às obras. Essa dinamicidade não desvaloriza o produto artístico que é entregue ao público, mas trata-se, sim, de uma dessacralização dessa obra que é apresentada. $O$ artista enfrenta, então, um processo de incertezas e mutações, que leva o produto artístico como algo que está sempre em constante processo. Partindo deste pensamento, como, então, relacionar a luz cênica como um objeto artístico com uma variação contínua?

\section{A luz no processo de construção da Cena}

Refletindo a realidade do trabalho em iluminação cênica num âmbito mais geral, os que exercem o trabalho com a luz cênica compreendem a iluminação, de modo mais tradicional, quando não inserida num processo de criação coletiva, entra no último momento da criação do espetáculo, em alguns casos, semanas antes da estreia. A luz é pensada à parte. $O$ processo criativo do iluminador, em alguns casos, é solitário, assistindo aos vídeos do espetáculo, realizando suas pesquisas individuais para criação, com a finalidade de conceber um projeto e/ou uma dramaturgia da luz.

Ressaltamos aqui que quando citamos dramaturgia da luz, não é ponderando que a luz sozinha vá narrar uma história, mas que a partir do jogo com a cena é que ela poderá transmitir informações. Dramaturgia da luz como uma construção de signos a partir da luz, no jogo com a cena e na relação com outras dramaturgias próprias da cena, compondo uma espécie de dramaturgia por texturas. Alguns pesquisadores e teatrólogos associam o termo Dramaturgia como elementos que se entrelaçam dentro da ação dramática, sendo esses entrelaçados como uma espécie de textura dramatúrgica. Como explicita Bonfitto (2011, p. 57-58):

\footnotetext{
A unidade estética nesses casos é resultante de um profundo jogo de tensões. Sendo assim, graças também à influência exercida pelos teatros orientais, não somente aquele balinês e chinês, mas também o indiano e o japonês, dentre outros, emergem no Ocidente uma noção de dramaturgia vista enquanto operação através da qual elementos cênicos não convergem para um mesmo ponto, mas são entrelaçados de diversas maneiras, são "tecidos". Surge assim, de maneira mais consistente em algumas culturas do Oeste, a noção de "dramaturgia como textura".
}

Voltando a refletir sobre o cotidiano do trabalho com a iluminação cênica, percebemos que em alguns casos, os iluminadores não conseguem experimentar suas ideias criativas para luz antes da estreia. Neste caso, a ideia da luz perpassa apenas 
pelo imaginário do coletivo que estreará o espetáculo. O iluminador revela como está pensando a luz para cena e o ator passa a imaginar também como será essa luz e como se utilizará dela no decorrer do jogo (ação). Compreendemos que essa forma mais tradicional dificulta o trabalho dos atores, que não conseguem ensaiar e se utilizarem dessa luz para a criação de suas ações, já que não há a interação entre a luz e o movimento. Moura (2014, p.16) fala sobre a luz no processo criativo do ator.

Vejamos por exemplo o caso do ator: quando o mesmo começa a interagir com o
processo criativo da luz, passa a entendê-la como uma constituinte de uma gra-
mática da cena, que contribuirá para criação de sua personagem, principalmente
no que diz respeito, aos aspectos de atmosfera, tempo e emoção. Esse mesmo
processo de troca do ator pode ser estabelecido com todas as demais linguagens,
trata-se de uma fusão de experiências, de uma mistura, que passa a compor sua
poética e que reverberará em muitos outros processos criativos que vier participar

Para o iluminador, há, também, uma dificuldade na criação sem uma experimentação prévia da iluminação. Experimentar a luz no processo criativo, juntamente com a cena, traria uma gama maior de possibilidades de criação e diminuiria as chances de erro no jogo luz e cena, pois a luz cênica não se completa sem a ação, tal como afirma Camargo (2015, p.92): "as experiências com iluminação têm demonstrado que a luz só se realiza completamente quando posta em contato direto com a cena, em seu fluxo intenso e vivo, e não de modo separado, por escolhas e decisões a priori".

No dia da estreia, muitas vezes bastante corrida e com pouco tempo para as montagens, é onde se dá o nascimento da luz. É o primeiro momento que o iluminador pode realmente pôr em prática sua iluminação e que os atores podem contar com esse elemento novo, que deixa de ser apenas imaginário e que passará a compor o jogo de cena. Após a estreia e com a continuidade da temporada, o iluminador poderá executar as correções.

Por intermédio de nossas experiências profissionais com direção, iluminação e operação de luz, percebemos que com alguma frequência, nos deparamos com uma resistência de alguns técnicos de iluminação que possuem uma ideia fixa de que quando uma luz está montada não se deve mais mexê-la e/ou, realizar mudanças durante o processo de execução do espetáculo ou das temporadas, gerando uma dificuldade no processo de criação contínua da luz.

Para Camargo (2015), há diferenças entre prever o efeito da luz sobre a cena e o resultado concreto que se vê no palco. Só através da experiência da luz em relação a cena é que se consegue obter uma resposta das propostas prévias almejadas, nesse caso, não se resumindo apenas no envio da luz, mas na resposta dos corpos e objetos em termos de reflexão, absorção e refração. Com isso, reafirmamos a fala de Camargo (2015, p. 91): "só é possível perceber como se dará o resultado da luz em cena quando radiações eletromagnéticas passam a interagir com o eletromagnetismo dos corpos".

Como lidar com a resistência de alguns técnicos de iluminação quando as mudanças se fizerem necessárias? Por que existe uma dificuldade grande em convencer alguns técnicos sobre a necessidade de alteração na luz?

Além das experiências profissionais que citamos, prestamos serviços como técnicos de iluminação para alguns Teatros e/ou Centros Culturais, em Fortaleza. 
Quando estamos compondo alguma equipe técnica, percebemos certa resistência às alterações. Outro fator que percebemos que quando são montagens de espetáculos locais, ou de companhias que ainda estão na busca de se firmarem na cena teatral, alguns técnicos dificultam ainda mais as mudanças. Quando são espetáculos de companhias consolidadas ou de outros estados, a resistência é menor, ou não existe. Acreditamos que essa seja a realidade que muitas companhias e iluminadores encontram no início da profissão. Isso é também um problema ético. Um dos fatores que, talvez, contribua para isto seja a falta de estudo e reflexão acerca da luz. O perfil profissional é mais operário, de aprendizado na prática. Não há, ou desconhecemos, cursos de nível técnico profissional para iluminadores cênicos e nem uma formação acadêmica para iluminadores no país, uma questão que abrangeria um debate muito maior, como sabemos. Geralmente, os profissionais costumam aprender no decorrer da prática de seus trabalhos, diariamente, na maioria dos casos somente a parte técnica da luz, deixando de lado os elementos estéticos, relacionados ao pensamento da luz cênica como linguagem artística.

Ainda como técnicos de iluminação, num teatro, percebemos em determinadas ocasiões que algumas criações ou execução de luz se apresentavam mais como elemento decorativo, se relacionando pouco com a ação cênica. Esse fator nos fez refletir pois, ocasionalmente, é perceptível que essas criações não contribuem muito com a obra. Passamos a perceber que alguns iluminadores/operadores de Luz parecem se preocupar apenas com a beleza da imagem produzida pela luz, tornando o trabalho às vezes com muitas mudanças de luz, estabelecendo uma luz sem jogo com a cena, sem a construção do signo, causando uma falta ou excesso de informação, em certos momentos cansando fisiologicamente o olho de quem vê a cena. Não há, nesses casos, a compreensão de que luz e cena são elementos que se complementam para a construção da linguagem e potencialização da ação, através da interferência de um elemento em outro.

Enquanto técnicos de iluminação no Teatro Dragão do Mar (Fortaleza), nos deparávamos com o fato de que a grande maioria das companhias locais chegava sem operador de luz e sem projeto de iluminação do espetáculo e, muitas vezes, acabávamos executando estas luzes, sem o conhecimento do espetáculo. A partir de então, refletimos que quando não há a compreensão da cena pelo operador de luz, nessa, e em outras ocasiões, resulta numa operação de luz feita de forma mais burocrática, técnica do sentido de conhecimento das mesas, digitais ou analógicas, mas sem a sensibilidade dos tempos e emoções das cenas.

Apesar da luz ser algo técnico, que necessite de conhecimentos sobre eletricidade, eletrônica, sistemas, computação, entre outros, ela é, também, a relação entre luz e cena. Nesse caso, se faz necessário conhecer os aspectos, linguagens e conceitos que envolvem a cena. Bonfanti (2015) aponta que o ensino regular da luz cênica é uma possibilidade de transformação do paᄀnorama atual do mercado, inserindo profissionais da iluminação que estudaram e se prepararam para a profissão e, ainda que tivessem muito a desenvolver com a prática, eles já chegariam com uma base de conhecimento mais sólida, mais científica.

Outro fator que talvez contribua para a resistência dos técnicos de iluminação seja a carga horária alta e as más condições de trabalho que alguns teatros oferecem 
aos seus profissionais, como salários abaixo do piso da categoria, falta de equipamentos de proteções individuais (EPI's), falta de salubridade, a precariedade dos equipamentos técnicos e outros descasos que acontecem aqui em Fortaleza e, acreditamos, que Brasil afora, fazendo com que os profissionais trabalhem desmotivados ou sem condições de executarem um bom serviço. Essa problemática é bem salientada por Bonfanti (2015, p.12): “No campo profissional vê-se a informalidade imperando, com profissionais des ᄀpreparados, curiosos e uma série de relações de trabalho que colocam a luz em lugar de total improviso".

\section{A luz como agente co-criador do espetáculo}

Uma função importante da iluminação é ampliar ou modificar o valor semiológico da cena. Para Salles (2008), a interferência, no ponto de vista do processo criativo artístico de uma forma geral, pode ser observada através das transformações que se operam na medida em que essas interações modificam os elementos envolvidos. Observa Salles (2008, p.28): “Essas modificações nos levam a um novo campo semântico que nos parece ser de grande importância: dar nova feição; tornar diferente do que era; mudar, alterar, modificar, transfigurar, converter, metamorfosear". A iluminação cênica é uma linguagem artística, estabelecida em relação com a ação da cena. A luz, enquanto objeto artístico, poderá estar em processo contínuo, com a possibilidade de que haja mudanças em relação a sua estrutura de montagem e execução, já que se houver uma mudança na cena, quer seja de movimento, tempo, espaço etc., a luz também estará sendo afetada por conta da relação direta com a cena. No jogo luz-cena há uma interação e interferência dos elementos.

Como operadores de luz, partimos do princípio de que somos parceiros da cena, contracenando com atores e espaço. É interessante que o operador não esteja somente assistindo uma obra e trocando a luz no momento das deixas, como algo que denominamos aqui de burocrático. A operação de luz é o momento em que a iluminação se realiza, tornando-se arte, onde lhe é dado o devido sentido semiológico através da cena, a realização da verdade artística. A operação de luz exige um estado de atenção, onde por meio do jogo cênico, há a modificação da cena por meio da luz e da luz por meio da cena.

No espetáculo canadense Container ${ }^{3}$, da bailarina canadense Vanessa Goodman e desenho de luz de James Proudfoot, o qual fizemos a montagem, afinação de luz e programação da mesa na apresentação que ocorreu durante a Bienal Internacional de Dança do Ceará, percebemos no espetáculo, que há um jogo de ações o tempo todo entre dança (movimento) e luz, um elemento depende do outro. Ocorre durante todo o espetáculo uma inter-relação entre estes elementos. Em alguns momentos parece que ela dança com a luz, ora ela propõe a mudança de luz pelo movimento, ora o movimento da bailarina propõe a mudança de luz. Para Camargo (2015), as negociações entre as informações provenientes da luz e as da cena constituem um

\footnotetext{
${ }^{3}$ Container estreou em 9 e 10 de junho de 2015, no Small Stage do Canada Dance Festival no Magnetic North Theatre Festival no National Arts Arts Centre, em Ottawa. Criado com suporte do Small Stage e The Shadbolt Center for The Arts, Container é um trabalho da coreógrafa e performer Vanessa Goodman que explora herança, cultura e resiliência. Apresentou-se na Bienal Internacional de Dança do Ceará, no Teatro Dragão do Mar, em Fortaleza, no dia 21.10.2017. Link do vídeo do espetáculo: https://www.youtube.com/watch?v=2TLJghg_AK4 (Título: Vanessa Goodman / Action at a Distance - 2016 Risk/Reward Festival).
} 
fluxo contínuo em que não existe passado nem futuro, apenas o momento presente, em que se dão os impactos e os acordos entre as duas partes envolvidas.

\section{O processo contínuo: a luz durante as temporadas}

Após a estreia do espetáculo, existe sempre a possibilidade de modificações de cenas. O iluminador criador da luz (Lighting Designer), em alguns casos, participa somente do processo criativo e das primeiras apresentações. Quem, então, deve ficar responsável pelas mudanças que se tornam necessárias durante o tempo em que o espetáculo estiver em processo?

Em alguns casos, a iluminação é repassada a um componente de coletivos artísticos. Geralmente, um ator do grupo que não está em cena. Esse, inclusive, é um dos caminhos que levam alguns a se iniciarem na profissão. Apesar desse fator, percebemos, quando atuamos como técnico de iluminação de Teatro/Instituições Teatrais que, em alguns casos, os espetáculos perdem muito em relação a iluminação no decorrer da temporada, por não haver uma reflexão da luz em relação a cena.

Às vezes, os responsáveis pela execução da luz acabam tomando algumas decisões sem base conceitual que resultam na quebra do jogo entre cena e luz. Outro fator que percebemos é que quando essa luz é repassada para alguns técnicos de iluminação, eles acabam, em alguns casos, pondo suas ideias e criando outra luz, diferente do projeto original.

É possível que isso não ocorra quando o Lighting Designer trabalha com uma equipe, contando com assistentes que saibam e respeitam o pensamento do criador da luz. Esses assistentes acompanham o espetáculo e executam as mudanças necessárias na luz, já que há necessidade de encaixar a luz a cada novo espaço, devido a diversidade de palcos, refletores, lâmpadas, varas etc.

Para Vasquez (2015), quando há uma temporada longa, o Lighting Designer deve acompanhar a montagem eventualmente para analisar se há mudanças de ritmo em cenas que devam ser retrabalhadas na programação da mesa de luz. A luz por si só já se modifica a cada novo espaço, arquiteturas e maquinárias, necessitando sempre de um novo olhar criativo para a adaptação da luz a cada novo espaço de atuação. Além das mudanças que ocorrem em diferentes tipos de palco, há também mudanças e evoluções da cena, como a descoberta de novas dinamicidades no jogo, mudança de tempos, pausas, mudanças de movimentações e outras variações.

Como operadores de luz do espetáculo Máquina Fatzer ${ }^{4}$, do Teatro Máquina 5 , que estreou em 25 de julho de 2014, no Teatro Dragão do Mar em Fortaleza, até a atualidade, passamos por muitas mutações em relação a luz e cena. Não somente com acréscimos de equipamentos, mas por uma readequação da afinação da luz e da operação no tempo de algumas cenas. Na estreia, o Lighting Designer Walter Façanha passou a concepção do projeto luminotécnico e a dramaturgia da luz para

\footnotetext{
${ }^{4}$ Na encenação do Teatro Máquina, o grupo dá forma à narrativa com tensão, repetição e engajamento físico e construção/destituição de uma língua em invenção. O espetáculo parte de fragmentos do Fatzer, escrito por Brecht entre 1926 e 1931.

${ }^{5}$ Teatro Maquina é um grupo de Fortaleza, no Ceará. Um coletivo que se reúne diariamente para pensar e praticar formas de se manterem juntos. Investigam o corpo e a presença, o gesto em sua decupagem, a palavra como imagem. Site: http://teatromaquina.weebly.com
} 
acompanharmos a peça no decorrer das temporadas. O espetáculo circulou por alguns festivais nacionais e pelo Palco Giratório do SESC, no circuito nacional no ano de 2016. Durante esse período, a cena foi evoluindo. O espetáculo também trabalha um pouco com o improviso, onde foram necessárias mudanças da luz em alguns aspectos a pedidos e juntamente à direção e atores. Quando há uma questão mais complexa, entramos em contato com o Lighting Designer para alguma solução. Da estreia até hoje, houve algumas mudanças de tempo, de posições dos atores e modificações de posições em algumas cenas que interferiram na luz. Apesar das mudanças, a ideia principal que permeia a dramaturgia da luz no espetáculo é sempre tomada de base a cada mudança que se faz necessária na luz.

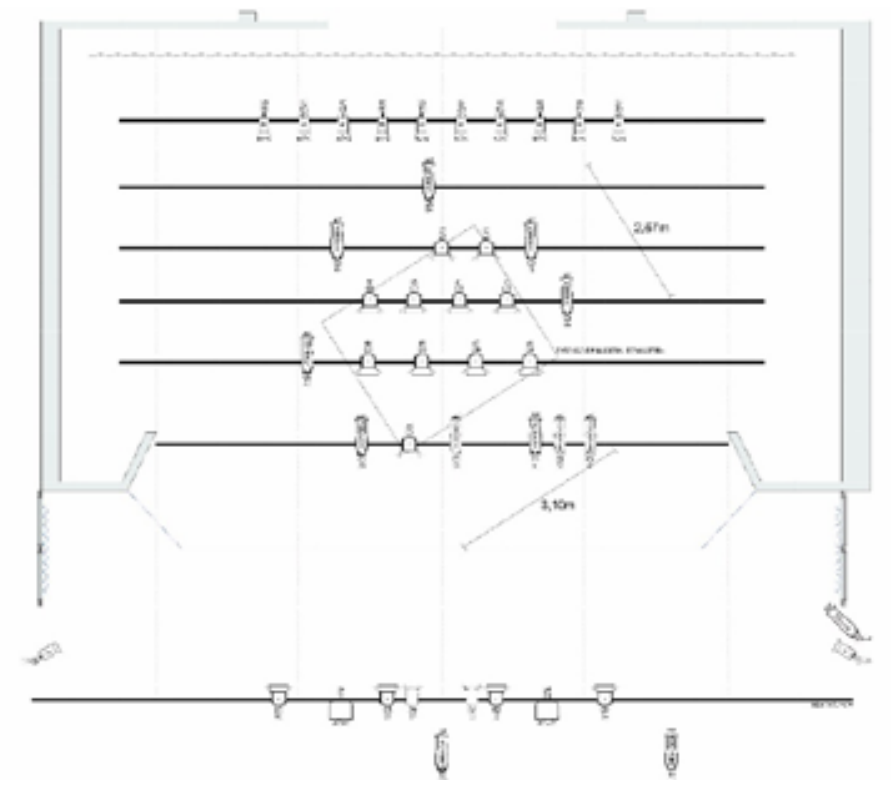

Figura 1 - Mapa de Luz do Espetáculo Máquina Fatzer - Diga que você está de acordo. Desenho de luz: Walter Façanha. Fonte: Acervo Autores

Conhecer a dramaturgia e a ideia do criador da iluminação fez com que a luz continuasse contribuindo com o jogo de cena, mesmo sem o Lighting Designer. Seguir a base dramatúrgica da luz, resulta numa "não quebra" do jogo luz-cena durante as apresentações e no decorrer das temporadas do espetáculo e faz com que a luz se fortaleça juntamente à ação.

Operar uma luz é uma relação de contracenação proposta entre luz e cena. De modificações e mutações, entre as ondas de radiação eletromagnéticas e os movimentos, a ação, corpos e objetos. Larrosa (2002) fala sobre a experiência como algo que nos passa, que acontece conosco e nos transforma, da sensibilidade e da busca da verdade possível no trabalho artístico. Toda ação praticada numa experiência modifica quem a pratica e quem a sofre.

Em Máquina Fatzer, estamos dentro da cena. Fazemo-nos presente dentro daquela casa também, sendo o elemento luz que vai modificar e perpassar pelas ações dos corpos e dos movimentos ator/personagem. A arte teatral é efêmera, cada cena, por mais que apresentadas muitas vezes, é única no seu instante de apresentação. Por mais que o operador saiba os tempos por meio do projeto luminotécnico do espetáculo, todo momento é novo. 
Lighting Designer propõe em Fatzer uma luz mais realista, compondo cenário, criando sombras. Em uma das cenas, o iluminador propõe uma iluminação mais escura, onde vamos diminuindo a intensidade da luz e um dos atores desliga uma lâmpada, na qual também temos o controle na mesa. Em uma apresentação no FILTE (Festival Latino Americano de Teatro da Bahia), edição de 2017, no Teatro Martin Gonçalves, em Salvador, durante a cena em que os personagens vão adormecendo e para isso apagam as lâmpadas, um dos atores esqueceu de apagar uma das lâmpadas. Nesse momento, havia, então, uma luz que sobrava em cena e que atrapalharia na cena seguinte, que era ainda mais escura. Foram poucos minutos em que era preciso compreender a dramaturgia da cena: não podíamos apagar aquela lâmpada pois quebraríamos a verdade da cena ou realizarmos algum movimento na luz que pudesse desviar a atenção da ação da atriz que estava em foco. Na ação seguinte após a cena, a atriz inseriu em suas ações o apagar da lâmpada.

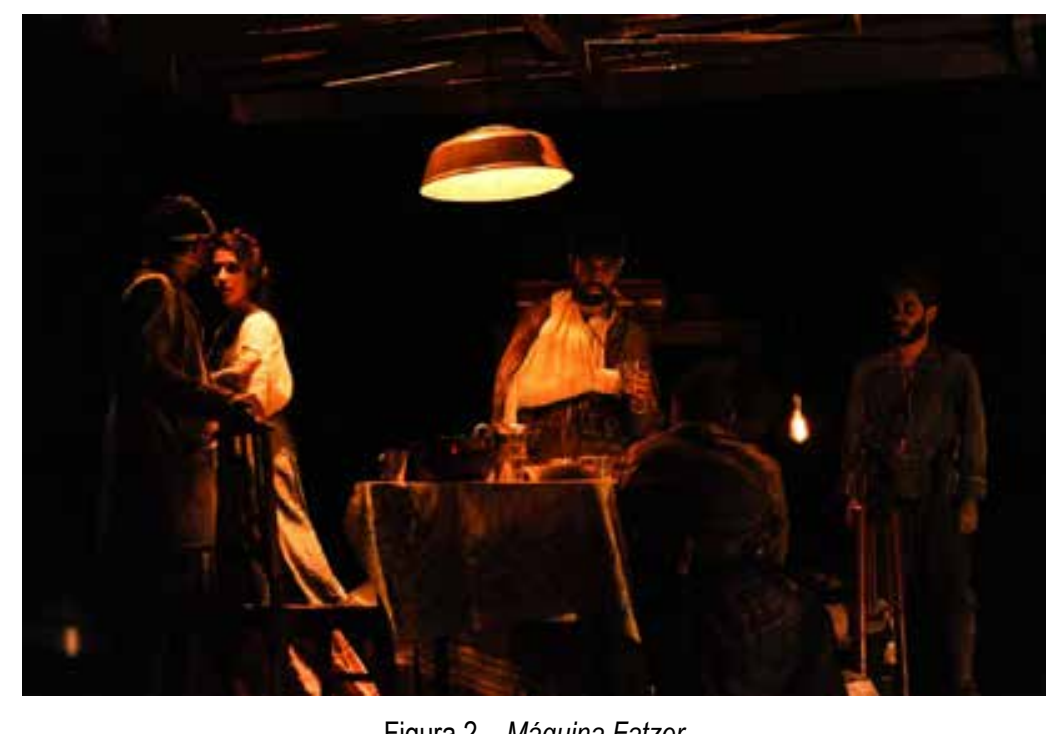

Fonte: Arquivo Teatro Máquina. Foto: Deivyson Teixeira

As mudanças quanto a refletores, relacionado a quantidade, tipo ou posição, por algumas das vezes também ocorrem. O Lighting Designer, ao nosso ver, deveria também acompanhar esse processo contínuo do espetáculo e da luz, redesenhando, se possível, percebendo as mutações e modificações. Não propomos que o iluminador deva fazer sempre mudanças, tornando seu projeto inconstante, mas que a luz deva acompanhar a cena e que haja uma atenção enquanto a iluminação no processo de continuidade dos espetáculos.

Em Container, o Lighting Designer teve o cuidado de redesenhar seu projeto para a apresentação que o espetáculo fez no Teatro Dragão do Mar, em Fortaleza, já realizando as adaptações e posições dos refletores, graus dos refletores elipsoidais. Esse novo desenho trouxe mais segurança para a técnica de luz responsável por executar o projeto.

Outra situação que envolve os projetos luminotécnicos e que ocorre enquanto mudança na luz no decorrer das apresentações é um projeto luminotécnico desatualizado, que não corresponde mais com o projeto de luz do espetáculo. Isso dificulta, pois através dos projetos luminotécnicos é que as instituições e festivais analisam 
as necessidades de adquirirem novos equipamentos para receberem os espetáculos. Esse fator pode resultar em uma perda financeira, pois às vezes são adquiridos novos materiais que acabam não sendo utilizados. Ou, também, resistência para se acrescentar algum equipamento que passou a ser utilizado na cena após a criação do projeto luminotécnico.

Por fim, concluímos de forma breve, que seja interessante pensarmos a continuidade criativa da iluminação de forma que a mesma prossiga potencializando a cena. É relevante refletirmos essa relação com a ação, quebrando a resistência de alguns profissionais, por intermédio da ampliação do estudo da luz cênica, assim como, buscarmos a melhoria das condições de trabalho nos locais em que se faz necessária. O diálogo entre os profissionais Lighting Designer, operador de luz e as companhias, ajudam na continuidade do processo dos espetáculos facilitando o trabalho dos técnicos de iluminação e o planejamento da produção dos festivais e das instituições culturais.

\section{Referencias}

BONFANTI, Guilherme. A luz no Teatro da Vertigem: processo de criação e pedagogia. Sala Preta, v. 14, n. 2, 2015, p. 10-21.

BONFITTO, Matteo. Tecendo os sentidos: a dramaturgia como textura. Pitágoras 500, v. 1, n. 1, 2011, p. 56-61.

CAMARGO, Roberto Gill. Luz e cena: impactos e trocas. Sala Preta, v. 14, n. 2, 2015, p.89-98.

LARROSA BONDÍA, Jorge. Notas sobre a experiência e o saber de experiência. Revista Brasileira de Educação, jan/fev/mar/abr 2002, n.19, p.20-28. Disponível em: http:// www.scielo.br/sciel.php?script=sci_arttex\&pid=s1413-

MOURA, Luiz Renato Gomes. A iluminação cênica no trabalho do ator de teatro. 2014. Dissertação de Mestrado. Universidade Federal do Rio Grande do Norte.

SALLES, Cecília Almeida. Redes da criação, construção da obra de arte. 2 ${ }^{a}$. ed. São Paulo: Editora Horizonte, 2008.

VÁZQUEZ, Rodolfo García. Luzes e sombras na trajetória dos Satyros. Sala Preta, v. 14, n. 2,2015, p. $30-40$.

Recebido em: 20/11/2017

Aprovado em: 01/03/2018 